\title{
Cross-infection Potential of Colletotrichum gloeosporioides Penz. Isolates Causing Anthracnose in Subtropical Fruit Crops
}

\author{
B.K.M. Lakshmi ${ }^{*}$, P. N. Reddy ${ }^{1}$ and R.D. Prasad $^{2}$ \\ Vegetable Research Station \\ Andhra Pradesh Horticultural University, Hyderabad- 30 \\ Andhra Pradesh, India
}

\begin{abstract}
Anthracnose, caused by Colletotrichum gloeosporioides Penz. is considered the most important disease in fruit crops in the humid tropics that contributes significantly to preharvest and postharvest losses in mango, papaya, guava, custard apple, pomegranate and other subtropical fruit crops. The objective of this study was to test the ability of the pathogen $\underline{C}$. gloeosporioides isolates from seven alternate fruit crops viz., mango, acid lime, custard apple, pomegranate, papaya, cashew and guava to cause disease by cross infection between fruit crops. Information on less infection would facilitate the design of an integrated approach for controlling the preharvest and postharvest losses due to anthracnose under mixed cropping systems especially in mango. Cross inoculation experiments demonstrated variation in the level of host preference and Percent Disease Index (PDI) among $C$. gloeosporioides isolates. The results revealed that among different fruit crops mango, cashew, pomegranate and custard apple were highly susceptible to the anthracnose disease. Isolate of $\underline{C}$. gloeosporioides obtained from mango developed anthracnose symptoms on seedlings on all alternative fruit crops tested except on papaya, but it developed the symptoms on fruits of papaya. Mango isolate recorded maximum PDI of 86.7 on fruits of custard apple and minimum on acidlime fruits (12.8 PDI). The $\mathrm{C}$. gloeosporioides isolates obtained from acid lime, custard apple, pomegranate, cashew and guava could infect the mango leaves and fruits except the papaya isolate which failed to infect the leaves, but produced infection on fruits of mango. Maximum PDI of 19.8 was recorded on mango leaves when inoculated with isolate from cashew, and a minimum PDI of zero and 3.4 was recorded when the leaves were inoculated with papaya and acid lime isolates respectively. Among different isolates of $\underline{C}$. gloeosporioides, the cashew isolate was more virulent on mango leaves and fruits, followed by the custard apple and guava isolates.
\end{abstract}

Key words: Colletotrichum gloeosporioides, Cross inoculation, Fruit crops.

\section{INTRODUCTION}

Mango is one of the world's most important and esteemed fruits of the tropical and subtropical countries and is cultivated extensively as a commercial fruit crop in India, China, Indonesia, Thailand and Mexico. By virtue of its wide range, delicious taste, superb flavor, very high nutritive and medicinal value as well as great religio-historical significance, it is called the "King of the fruits" (Hayes, 1953). In India, it occupies an area of $19.61 \times 10^{5}$ ha (36.7\% of the total area devoted for fruit crops) with an annual production of 12537.9 MT,

To whom correspondence should be addressed to: laxmishreva@yahoo.com

Department of Plant Pathology, College of Agriculture, ANGRAU, Rajendranagar, Hyderabad-30, India

Directorate of Oil seeds Research, Rajendranagar, Hyderabad-30, India 
(21.3\% of total fruit production of India) and a productivity of 6.2 MT per ha. (National Horticulture Board Report, 2008-09).

Various biotic and abiotic stresses cause immense loss to mango crop throughout the world. Among biotic stresses, anthracnose caused by Colletotrichum gloeosporioides (Penz.) Penz \& Sacc. in Penz.(the fungus teleomorph Glomerella cingulata (Stoneman) Spauld \& Schrenk) is the most important and prevalent disease in all mango growing regions. It contributes significantly to preharvest and postharvest losses in mango and other fruit crops such as cashew, pomegranate, guava, acid lime and papaya. It is also manifested as leaf spot (Bird's eye disease), blossom blight or fruit rot (Prakash et al., 1996). Crop losses caused by C. gloeosporioides generally occur as a direct reduction in quantity or quality of the harvested produce. Freeman and Shabi (1996) reported that mango, papaya, custard apple, guava and pomegranate suffered mostly due to latent infection of the pathogen.

In general, mango is cultivated as sole crop in a wide range of soils and climatic conditions. However in early stages of its growth (up to 15 years) it is cultivated along with cashew, guava, custard apple and acid lime as a mixed crop. The problem of anthracnose incidence is compounded by the mixed cropping system of horticulture practiced in Andhra Pradesh. Hence a cross inoculation study was conducted to test the ability and level of host preference of different isolates of C. gloeosporioides isolated from tropical fruit crops to cause disease on mango and isolates of mango on other fruit crops, to provide information that would facilitate to develop an integrated system for controlling post harvest losses of produce due to anthracnose disease.

\section{METHODOLOGY}

C. gloeosporioides isolations were made from the leaves of mango (Mangifera indica L.), acid lime (Citrus aurantifolia), custard apple (Annona squamosa), pomegranate (Punica granatum L.), papaya (Carica papaya), cashew (Anacardium occidentale L.) and guava (Psidium guajava L.) showing typical symptoms of anthracnose disease by the tissue segment method (Rangaswami and Mahadevan, 1999), on potato dextrose agar medium (PDA). The fungus was further purified by single spore isolation method (Dhingra and Sinclair, 1993).The pathogen was identified as Colletotrichum gloeosporioides Penz., based on its mycelial, conidial characteristics through standard mycological keys (Barnett et al., 1972). Isolates were stored on PDA for further studies.

\section{Pathogenicity study}

\section{The effect on seedlings}

Pathogenicity of the different isolates of Colletotrichum gloeosporioides was tested by the spray inoculation method (Fitzell, 1979) on leaves of mango, acid lime, custard apple, pomegranate, papaya, cashew and guava seedlings. Each isolate of $C$. gloeosporioides collected from different fruit crops were artificially inoculated on mango leaves and the mango isolate was inoculated on leaves of other fruit crops seedling and subsequent anthracnose disease symptom development on leaves of seedlings were recorded to study the cross infection. For this leaves were slightly injured by the pin prick method and then inoculated by spraying spore suspensions of conidia $\left(4 \times 10^{4}\right.$ conidia $\mathrm{ml}^{-1}$ water) of each isolate. A hand atomizer was used for spraying the inoculum suspension of each isolate and 
atomizer was pre sterilized with $90 \%$ ethanol before the spraying of the inoculum each time. The inoculated seedlings were covered with transparent polyethylene bags of (100 gauge) $15 \mathrm{x} 10^{\prime \prime}$ for $48 \mathrm{~h}$ to ensure high humidity by spraying sterile distilled water to provide favorable conditions for conidial germination and infection.

\section{The effect on fruits}

Cross infection potential of isolates on different fruit crops were tested using matured healthy fruits of mango var. Baneshan, acid lime var. Balaji, custard apple var. Balanagar, pomegranate var. Bhaguva, papaya var. Red lady, cashew var. BPT 9 and guava var. Allahabad Safeda. Surface sterilized fruits were slightly injured with sterile needles aseptically and spray inoculated with $C$. gloeosporioides spore suspension $\left(4 \times 10^{4}\right.$ conidia $\mathrm{ml}^{-1}$ of water with $0.01 \%$ Tween 20 ). Fruits sprayed with sterile distilled water served as the control. Each set of fruits was incubated separately in moist chambers and covered with perforated polythene bags to maintain a high humidity necessary for infection and these bags were removed $48 \mathrm{hrs}$ after inoculation and maintained at room temperature $\left(28 \pm 2^{\circ} \mathrm{C}\right)$. Lesion development was measured daily for each fruit. The fungus was re-isolated from the lesions of infected fruits and its identity was confirmed.

Three replications each containing eight seedlings /fruits were inoculated and maintained for each fungal isolate. The experiment was repeated twice. Observations on type of lesion development and number of days taken for lesion development on leaves and fruits were recorded after inoculation. The disease severity on leaves and fruits were assessed using a 0 5 scale.

\section{Disease severity}

Disease severity on plant parts was recorded using a five point rating scale which was recommended by All India Co-ordinate Research Project on Sub-tropical Fruit Crops, Lucknow, India based on the percentage of leaf or fruit area affected by the disease, presented below.

\section{Leaf / fruit area affected}

No infection

Up to 5 percent

$6-10$ percent

$11-20$ percent

$21-50$ percent

More than 50 percent

\section{Grade}

1

2

3

4

5

\section{Percent disease index (PDI)}

Based on the numerical ratings given above a 'Percent disease index' for leaf blight and fruit rot was calculated using the formula (Mayee and Datar, 1986) given below:

Percent disease index (PDI) $=\frac{\text { Sum of numerical ratings X } 100}{\text { No. of units } * \text { examined X Maximum grade }}$

$*$ Unit $=$ Leaves $/$ fruits. 


\section{Virulence index (VI)}

The numerical values of Percent disease index and latent period were used to calculate the Virulence index using the following formula (Thakur and Rao, 1997).

Virulence index $(\mathrm{VI})=$ Per cent disease reaction $(\mathrm{PDI}) \mathrm{X}$ Latent period

\section{Statistical Analysis}

The experiment was carried out using a completely randomized design (CRD) with three replications, analysis was done to compare significant differences among the isolates for pathogenicity, Latent period and Virulence index (Gomez and Gomez, 1984).

\section{RESULTS AND DISCUSSION}

C. gloeosporioides has an extensive host range particularly in sub tropical areas. Crossinoculation experiments demonstrated variations in pathogenicity on their original host and on mango and mango isolates on other fruit crops. The level of host preference among $C$. gloeosporioides isolates from seven subtropical fruit crops and the susceptibility of the hosts varied significantly.

\section{Pathogenicity of $C$. gloeosporioides isolates on their original host}

C. gloeosporioides isolates were established as the causative organisms of anthracnose disease in the fruit crops tested and recorded maximum per cent disease index, virulence index and minimum incubation period on their original host (Table 1). The results revealed that among different fruit crops cashew (64.3, PDI), custard apple (61.8, PDI) and mango (51.4, PDI), were highly susceptible to anthracnose disease than acid lime, papaya and pomegranate. A minimum mean PDI of $21.9 \%$ was recorded in acid lime seedlings. Incubation period of $C$. gloeosporioides on an average was higher on leaves (9.7 days) compared to fruits (4.8 days). However, on fruits the maximum PDI and virulence index were recorded maximum on custard apple $(98.6 \%$ and $20.6 \%$, respectively) followed by cashew (88.4\% and $18 \%$, respectively). C. gloeosporioides isolates produced larger lesions on their original host when compared with the alternate hosts (Wijeratnam et al., 2008).

In the present study, the isolates of $C$. gloeosporioides from different fruit crops showed that C. gloeosporioides is the pathogen responsible for anthracnose in fruit crops. Sanders and Korsten (2003) reported that cross inoculation potential of C.gloeosporioides, isolates from avocado and mango showed larger lesions on their original hosts and produced lesions on all other hosts except citrus. Similar cross infectivity studies carried out by Colletotrichum spp. isolates from cashew, mango, papaya and passion fruit produced necrotic and depressed lesions on fruits, except on passion fruit, which was susceptible to its isolates only (Lima Filho et al., 2003) 
Table 1. Pathogenicity of $C$. gloeosporioides isolates on their original host

\begin{tabular}{|c|c|c|c|c|c|c|c|c|c|}
\hline \multirow{2}{*}{ Isolated from } & \multicolumn{3}{|c|}{ Percent disease index* } & \multicolumn{3}{|c|}{$\begin{array}{c}\text { Incubation period } \\
\text { (DAI)* }\end{array}$} & \multicolumn{3}{|c|}{ Virulence index* } \\
\hline & Leaves & Fruits & Mean & Leaves & Fruits & Mean & Leaves & Fruits & Mean \\
\hline$\overline{\text { Mango }}$ & $30.4(33.4)^{b}$ & $72.3(58.3)^{\mathrm{c}}$ & $51.4(45.8)^{\mathrm{b}}$ & $7.7^{\mathrm{d}}$ & $7.7^{\mathrm{a}}$ & 7.6 & $3.8 \mathrm{~b}$ & $9.4^{\mathrm{d}}$ & $6.6^{\mathrm{c}}$ \\
\hline Acid lime & $23.4(28.9)^{\mathrm{c}}$ & $20.5(26.9)^{\mathrm{e}}$ & $21.9(27.9)^{\mathrm{d}}$ & ${ }^{d} 15.3^{a}$ & $7.5^{\mathrm{a}}$ & 11.4 & $1.5 \mathrm{c}$ & $2.7^{\mathrm{e}}$ & $2.1^{\mathrm{d}}$ \\
\hline Custard apple & $25.1(30.0)^{\mathrm{c}}$ & $98.6(84.6)^{a}$ & $51.8(57.3)^{\mathrm{a}}$ & a $\quad 7.4^{\mathrm{d}}$ & $2.6^{\mathrm{d}}$ & 5.0 & $3.4^{\mathrm{b}}$ & $37.9^{\mathrm{a}}$ & $20.6^{\mathrm{a}}$ \\
\hline Pomegranate & $29.1(32.6)^{\mathrm{b}}$ & $43.5(41.3)^{\mathrm{d}}$ & $36.3(36.9)^{\mathrm{c}}$ & ${ }^{c} 10.9^{\mathrm{b}}$ & $4.9^{\mathrm{b}}$ & 7.9 & $2.6^{\mathrm{bc}}$ & $9.0^{\mathrm{d}}$ & $5.8^{\mathrm{c}}$ \\
\hline Papaya & $23.6(29.1)^{\mathrm{c}}$ & $43.9(41.5)^{\mathrm{d}}$ & $33.8(35.3)^{\mathrm{c}}$ & $8.3^{c}$ & $3.9^{\mathrm{bc}}$ & 6.1 & $2.6 \mathrm{bc}$ & $11.1^{\mathrm{d}}$ & $6.8^{\mathrm{c}}$ \\
\hline Cashew & $40.2(39.4)^{\mathrm{a}}$ & $88.4(70.3)^{\mathrm{b}}$ & $54.3(54.8)^{\mathrm{a}}$ & a $7.1^{\mathrm{e}}$ & $4.5^{\mathrm{b}}$ & 5.7 & $5.7^{\mathrm{a}}$ & $18.0^{\mathrm{c}}$ & $11.8^{\mathrm{b}}$ \\
\hline Guava & $22.7(28.5)^{\mathrm{c}}$ & $76.2(60.9)^{\mathrm{c}}$ & $49.5(44.7)^{\mathrm{b}}$ & $11.3^{\mathrm{b}}$ & $2.9^{\mathrm{d}}$ & 7.1 & $2.0^{\mathrm{c}}$ & $27.1^{\mathrm{b}}$ & $14.5^{\mathrm{b}}$ \\
\hline Mean & 27.8 & 63.3 & & 9.7 & 4.8 & & 3.1 & 16.5 & \\
\hline $\mathrm{SEm} \pm$ & 0.8 & 1.5 & 2.1 & 0.2 & 0.3 & 0.5 & 0.7 & 1.2 & 1.7 \\
\hline C.D $(\overline{\mathrm{P}}=0.05)$ & 1.6 & 3.1 & 4.3 & 0.4 & 0.7 & 0.9 & 1.3 & 2.5 & 3.6 \\
\hline
\end{tabular}

* Means of three replications in each treatment. **Figures in parentheses are arc sin transformed values.

*** Means with same letters were not significantly different within each column

\section{Cross infectivity of mango isolate of $C$. gloeosporioides on alternate fruit crops}

The isolate of $C$. gloeosporioides from mango caused infection on the leaves and fruits of each of these hosts; however, there was a significant variability in the degree of virulence. In fact, it showed typical symptoms of anthracnose on leaves and fruits of all the crops except on leaves of papaya. Table 2 indicates that there was a significant difference in preference of alternate host, maximum PDI of $22.6 \%$ was recorded on cashew leaves, whereas minimum PDI $(0 \%)$ was recorded on papaya followed by acid lime $(4 \%)$ and pomegranate $(8.4 \%)$ seedlings.

Table 2. Cross infection potential of $C$. gloeosporioides mango isolate on alternate fruit crops

\begin{tabular}{|c|c|c|c|c|c|c|c|c|c|}
\hline \multirow{2}{*}{$\begin{array}{l}\text { Isolated } \\
\text { from }\end{array}$} & \multicolumn{3}{|c|}{ Percent disease index* } & \multicolumn{3}{|c|}{$\begin{array}{c}\text { Incubation } \\
\operatorname{period}(\mathrm{DAI}) *\end{array}$} & \multicolumn{3}{|c|}{ Virulence index* } \\
\hline & Leaves & Fruits & Mean & Leaves & Fruits & Mean & Leaves & Fruits & Mean \\
\hline Acid lime & $4.0(11.4)$ & $12.8(20.9)$ & $8.4(16.1)$ & 19.9 & 11.5 & 15.7 & 0.1 & 0.7 & 0.4 \\
\hline Custard apple & $12.6(20.7)$ & 86.7 (68.7) & 49.6 (44.7) & 12.6 & 4.5 & 8.5 & 0.9 & 19.1 & 10.0 \\
\hline Pomegranate & $84(16.8)$ & $21.8(27.7)$ & $15.1(22.3)$ & 18.0 & 7.8 & 12.9 & 0.4 & 2.7 & 1.6 \\
\hline Papaya & $00(0.0)$ & $26.8(31.1)$ & $13.4(15.5)$ & 0.0 & 5.9 & 2.9 & 0.0 & 4.4 & 2.2 \\
\hline Cashew & $22.6(28.6)$ & $69.3(56.3)$ & $46.0(42.4)$ & 11.5 & 5.9 & 8.7 & 1.9 & 11.6 & 6.8 \\
\hline Guava & $10.5(18.9)$ & $60.4(51.0)$ & 35.5 (34.9) & 18.4 & 3.8 & 11.1 & 0.5 & 15.8 & 8.2 \\
\hline Mango & $30.4(33.4)$ & $72.3(58.3)$ & $51.3(45.8)$ & 7.7 & 7.6 & 7.6 & 3.8 & 9.4 & 6.6 \\
\hline Mean & 15.6 & 50.0 & & 12.6 & 6.7 & & 1.1 & 9.1 & \\
\hline $\mathrm{SEm} \pm$ & 0.6 & 1.2 & 1.8 & 0.1 & 0.3 & 0.4 & 0.2 & 0.5 & 0.7 \\
\hline C.D $(\mathrm{P}=0.05)$ & 1.4 & 2.6 & 3.7 & 0.3 & 0.7 & 1.0 & 0.5 & 1.0 & 1.4 \\
\hline
\end{tabular}

* Means of three replications in each treatment. **Figures in parentheses are arc sin transformed values.

**** Means with same letters were not significantly different within each column 
The mango isolate was more aggressive on fruits of custard apple (86.7, PDI), cashew (69.3, PDI) and guava (60.4, PDI) with an incubation period of 4.5, 5.9 and 3.8 days respectively than the other fruit crops. In contrast $C$. gloeosporioides collected from mango was less vigorous on acid lime fruits compared to other fruits inoculated and a PDI of 8.4 was recorded with a maximum incubation period of 11.5 days. In case of papaya, inoculation mango with isolate succeeded to produce symptoms on fruits, 26.8 PDI with an incubation period of 5.9 days. The mean maximum Virulence index of 10.1 was recorded on custard apple and minimum virulence of 0.49 was recorded in acid lime followed by pomegranate (1.6) which was similar with each other. Similar results were reported by Quimo and Quimo (1975) on differences in the degree of pathogenicity of mango isolates of $C$. gloeosporioides on mango, citrus and papaya to cause infection on fruits of each of these hosts but there was variability in the degree of pathogenicity.

\section{Cross inoculation studies of $C$. gloeosporioides collected from different fruit crops on Mango}

The isolates obtained from cashew, acid lime, custard apple, pomegranate and guava could infect the leaves and fruits of mango, except the papaya isolate which failed to infect the leaves of mango, but produced infection on mango fruits (Table 3). The isolate from cashew was more aggressive on leaves and fruits of mango and it recorded the maximum per cent disease index of 19.8 on leaves and $40 \%$ on fruits compared to other isolates with mean maximum VI of 4.1. Papaya, acid lime and pomegranate isolates were least effective on mango and caused a minimum PDI on leaves of mango ( $0,3.4$ and $4.3 \%$, respectively) and $21.8,9.3$ and $14.3 \%$, respectively on fruits. These isolates exhibited the symptoms of anthracnose on leaves of mango after maximum incubation period of 17.3 days when pomegranate isolate was inoculated, followed by acid lime isolate (16.8days) which similar to each other.

On fruits of mango, a mean minimum incubation period of 3.7 days was recorded with the papaya isolate on mango and mean maximum incubation period of 12.6 and 12.4 days were recorded with acid lime and pomegranate isolates respectively. Papaya isolate recorded a Virulence index of zero on leaves of mango and 2.8 on mango fruits with a mean virulence index of 1.4. It showed the lower preference of mango by papaya, acid lime and pomegranate isolates. Similar results were reported by Sharma and Verma (2007) that the isolates obtained from mango, citrus, guava had capability to infect the host of each other except the acid lime leaves. However, Xiao et al. (2004) studied mango, citrus and strawberry and proved the cross inoculation potential of these isolates among themselves.

Simmonds (1965) demonstrated that $C$. gloeosporioides isolates from fruit crops could readily cross-infect over a wide host range, however, isolates were most aggressive in infecting the host from which they were originally isolated. In the present study the isolates of $C$. gloeosporioides collected from fruit crops such as citrus, pomegranate, cashew and guava caused anthracnose disease on mango seedlings and fruits. But the disease index was less on mango compared to PDI on their original host. C. gloeosporioides from papaya failed to develop the anthracnose symptoms on leaves of mango, but it induced the anthracnose disease on mango fruits more than acid lime and pomegranate isolates of $C$. gloeosporioides. However mango isolate was more aggressive on custard apple and cashew than the other tested fruits even on mango, the original host. 
Table 3. Cross infection potential of $C$. gloeosporioides collected from different fruit crops on mango

\begin{tabular}{|c|c|c|c|c|c|c|c|c|c|}
\hline \multirow[t]{2}{*}{ Isolates } & \multicolumn{3}{|c|}{$\begin{array}{c}\text { Percent disease index on } \\
\text { mango* }\end{array}$} & \multicolumn{3}{|c|}{$\begin{array}{c}\text { Incubation } \\
\text { period(DAI)* }\end{array}$} & \multicolumn{3}{|c|}{ Virulence index* } \\
\hline & Leaves & Fruits & Mean & Leaves & Fruits & Mean & Leaves & Fruits & Mean \\
\hline Mango & $30.4(33.4)$ & $72.3(58.3)$ & $51.2(45.9)$ & 7.7 & 7.6 & 7.6 & 3.9 & 9.4 & 6.7 \\
\hline Acid lime & $3.4(10.5)$ & $9.3(17.6)$ & $6.4(14.0)$ & 16.8 & 8.5 & 12.6 & 0.2 & 1.1 & 0.6 \\
\hline Custard apple & $11.2(19.5)$ & $19.2(25.9)$ & $15.2(22.7)$ & 9.6 & 7.6 & 8.66 & 1.1 & 2.5 & 1.8 \\
\hline Pomegranate & $4.3(11.8)$ & $14.3(22.1)$ & $9.3(16.9)$ & 17.3 & 7.4 & 12.4 & 0.2 & 1.9 & 1.1 \\
\hline Papaya & $0.0(0.0)$ & $21.8(27.8)$ & $10.9(13.8)$ & 0.0 & 7.5 & 3.7 & 0 & 2.8 & 1.4 \\
\hline Cashew & $19.8(26.4)$ & $40.0(39.2)$ & $29.9(32.8)$ & 9.7 & 6.9 & 8.3 & 2.5 & 5.8 & 4.1 \\
\hline Guava & $6.5(14.7)$ & $22.5(28.3)$ & $14.5(21.5)$ & 13.1 & 7.4 & 10.2 & 0.5 & 3.0 & 1.7 \\
\hline Mean & $10.8(16.6)$ & $28.4(31.3)$ & & 10.6 & 7.5 & & 1.2 & 3.8 & \\
\hline $\mathrm{SEm} \pm$ & 0.7 & 1.3 & --- & 0.2 & 0.4 & 0.6 & 0.1 & 0.2 & 0.3 \\
\hline C.D $(0.05)$ & 1.4 & 2.7 & NS & 0.5 & 0.8 & 1.3 & 0.3 & 0.5 & 0.7 \\
\hline
\end{tabular}

* Means of three replications in each treatment. **Figures in parentheses are arc sin transformed values

**** Means with same letters were not significantly different within each column

A single host may be infected by several Colletotrichum sp or a single species of Colletotrichum may infect more than one host (Alahakoon et al., 1994; Bernstein et al., 1995; Freeman and Shabi 1996 and Xiao et al., 2004). As many hosts susceptible to $C$. gloeosporioides are cultivated, the losses in fields where mango, cashew, custard apple and guava are grown in close proximity could be high. Similar results were reported by Freeman et al. (1998) in mango, avocado, papaya and citrus in cross inoculation studies. Based on the present results, it can be concluded that in nature, inoculum may be dispersed from one crop to other crops. Further, such ability of the pathogen may provide an opportunity to the pathogen to survive during adverse periods in crops. In epidemiological studies it is essential to consider the source of inoculum from these sources in addition to infected debris.

The differences in capability of various isolates of $C$. gloeosporioides to invade different kinds of fruits tested can be attributed to variations in the composition of each kind of fruit. The available data of the present experiment suggests that the $C$. gloeosporioides is more pathogenic on fruits than on leaves. The isolates from mango and papaya failed to infect the leaves of alternate hosts but successfully penetrated the intact fruits. This might be due to accessibility of substrates such as pectin and cellulose for induction and secretion of cell wall degrading enzymes or due to the presence of cutinolytic enzymes secreted by the pathogen (Dickman, 1994). Prusky and Plumbley (1992) suggested that the susceptibility of fruits to Colletotrichum infection is related to the level of antifungal inhibitors present in these fruits. Vercesi et al. (1997) found that fruit exudates may significantly affect pathogen growth at an early stage of infection.

Isolates obtained from mango and cashew were the most pathogenic on leaves of the other fruit crops. This suggested that adaptation of $C$. gloeosporioides on relatively resistant hosts has resulted in the generation of more virulent isolates of the pathogen. Omar (2001) collected five isolates of $C$. gloeosporioides from diseased guava fruits and it successfully invaded mango, pear and apple fruits. However, the five isolates showed different pathogenic potential towards the four tested fruits. Enzyme activity was significantly different among these isolates. 


\section{CONCLUSION}

The cross inoculation experiments demonstrated variations in the level of host preference among $C$. gloeosporioides isolates from different fruit crops. Among the different fruit crops, mango, cashew and custard apple were highly susceptible to the anthracnose disease. The isolates of $C$. gloeosporioides obtained from acid lime, custard apple, pomegranate, cashew and guava could infect the mango leaves and fruits except papaya isolate which produced infection only on mango fruits. Among different isolates of $C$. gloeosporioides, the cashew isolate was more virulent on mango leaves and fruits followed by custard apple and guava isolates. This study established the possibility of cross infection between host organisms in the case of seven isolates of $C$. gloeosporioides with respect to examined varieties of hosts. This could result in the development of model orchards of mango mixed cropping systems, with the motto of an integrated, safe and convenient means of reducing post harvest losses in fruit crops.

\section{REFERENCES}

Alahakoon, P. W., Brown, A. E., and Sreenivasa Prasad. S. (1994 ). Cross-infection potential of genetic groups of Colletotrichum gloeosporiodies on tropical fruits. Path. and Mol. Plant Path. 44, 93-103.

Barnett, H. L. and Barry, B., Hunter. (1972). Illustrated genera of imperfect fungi. Burgeos Publishing Company, Minnesota.

Bernstein, B., Zehr, E. I., Dean. R. A. and Shabi, E. (1995). Characteristics of Colletotrichum from peach, apple, pecan and other hosts. Plant Dis. 79, 478-482.

Dhingra, O. D. and Sinclair, J., B. (1993). Basic Plant Pathology methods. CBS Publications and Distribution, New Delhi, India. p. 335.

Dickman, K.B. (1994). Part V. Papaya: Anthracnose. pp. 58-59 In: Compendium of Tropical Fruit Diseases. Ploetz, R.C. Zentmyer, G.A., Nishijima, W.T. Rohrbach, K.G. \& Ohr, H.D. (Eds.) APS Press, St Paul, Minnesota.

Fitzell, R. D. (1979) Colletotrichum acutatum as a cause of anthracnose of mango in New South Wales. Plant Dis. Reporter. 63, 1067-1070.

Freeman,S., Katan, T. and Shabi, E. (1998). Characterisation of Colletotrichum species responsible for anthracnose diseases of various fruits. Plant Dis. 82, 596-605.

Freeman, S. and Shabi, E. (1996). Cross-infection of subtropical and temperature fruits by Colletotrichum species from various hosts. Physiological and molecular Plant Path. 49, 395 - 404.

Gomez, K.A. and Gomez, A.A. (1984). Statistical procedures for agricultural research $2^{\text {nd }}$ Ed., John Wiely and Sons, New York, NY.

Hayes,W. B .(1953). Fruits Growing in India, Kitabistan, Allahabad, India.

Lima Filho, R. M., Oliveira, S. M. A., Menezes, M. (2003). Enzymatic characterization and crossed pathogenicity of Colletotrichum spp. associated with post harvest diseases. Fitopatologia Brasileira. 28(6), 620-625. 
Mayee,C.D. and Datar, V.V (1986). Phytopathometry. Marathwada Agricultural University, Parbhani, p 95.

National Horticulture Board Report. (2008-09).http://www.nhb.gov.in/statistics/areaproduction-statistics.html.

Walid, O.A. (2001). Occurrence of Colletotrichum anthracnose disease of guava fruit in Egypt. International J. Pest Mgt. 47(2), 147-152.

Prakash, O. M., Misra, A. K. and Pandey, B. K. (1996). Anthracnose diseases of tropical and sub tropical fruits. In: Disease Scenario in Crop Plants. Vol.I, Fruits and Vegetables. (Eds. V.P. Agnihotri, Om Prakash, Ram Kishen and A.K.Misra).

Prusky, D. and Plumbley, R.A. (1992). Quiescent infections of Colletotrichum in tropical and subtropical fruits. Pp 289-307.In Colletotrichum: Biology, Pathology and Control [edited by Bailey, J.A.; Jeger, M.J.] CAB International, Wallingford, UK.

Quimio, T. H. and Quimio, A. J. (1975). Pathogenicity of mango anthracnose. The Philippine Agriculturist 58, 322-329.

Rangaswami, G. and Mahadevan, A. (1999). Diseases of Crop plants in India. Prentice Hall of India Pvt. Ltd., New Delhi, India. pp 65-66.

Sanders, G. M. and Korsten, L. (2003). Comparison of cross inoculation potential of South African avocado and mango isolates of Colletotrichum gloeosporioides. Microbiol. Res. 158(2), 143-150.

Simmonds, J. H. (1965). A study of the species of Colletotrichum causing ripe fruit rots in Queensland. Queensland J. Agric. and Animal Sci. 22, 437-459.

Sharma Abishek. and Verma, K. S. (2007). In vitro cross pathogenicity and management of Colletotrichum gloeosporioides causing anthracnose of Mango. Annals of Plant Prot. Sci. 15(1), 186-188.

Thakur, R.P.and Rao,V.P.(1997).Variation in virulence and aggressiveness among pathology of Sclerospora graminicola on pearl millet. Ind. Phytopath. 50, 40-47.

Vercesi, A., Locci, R. and Prosser, J. I. (1997). Growth kinetics of Botrytis cinerea on organic acids and sugars in relation to colonization of grape berries. Myco. Res. 101, 139142.

Wilson, W.S, Dharmatilaka, Y. and Weerasinghe, D. (2008). Host specificity of Colletotrichum gloeosporioides and Botryodiplodia theobranae isolates from mango, papaya and rambutan and their response to Trichodesma harzianum. Conference on International Research on Food security, Natural Resource Management and Rural Development. University of Hohenheim, Oct 7-9.

Xiao, C. L., Mackenzie, S. J. and Legard, D. E. (2004). Genetic and pathogenic analyses of Colletotrichum gloeosporioides from strawberry and non-cultivated hosts. Phytopath. 94, 446-453. 
Lakshmi et al.

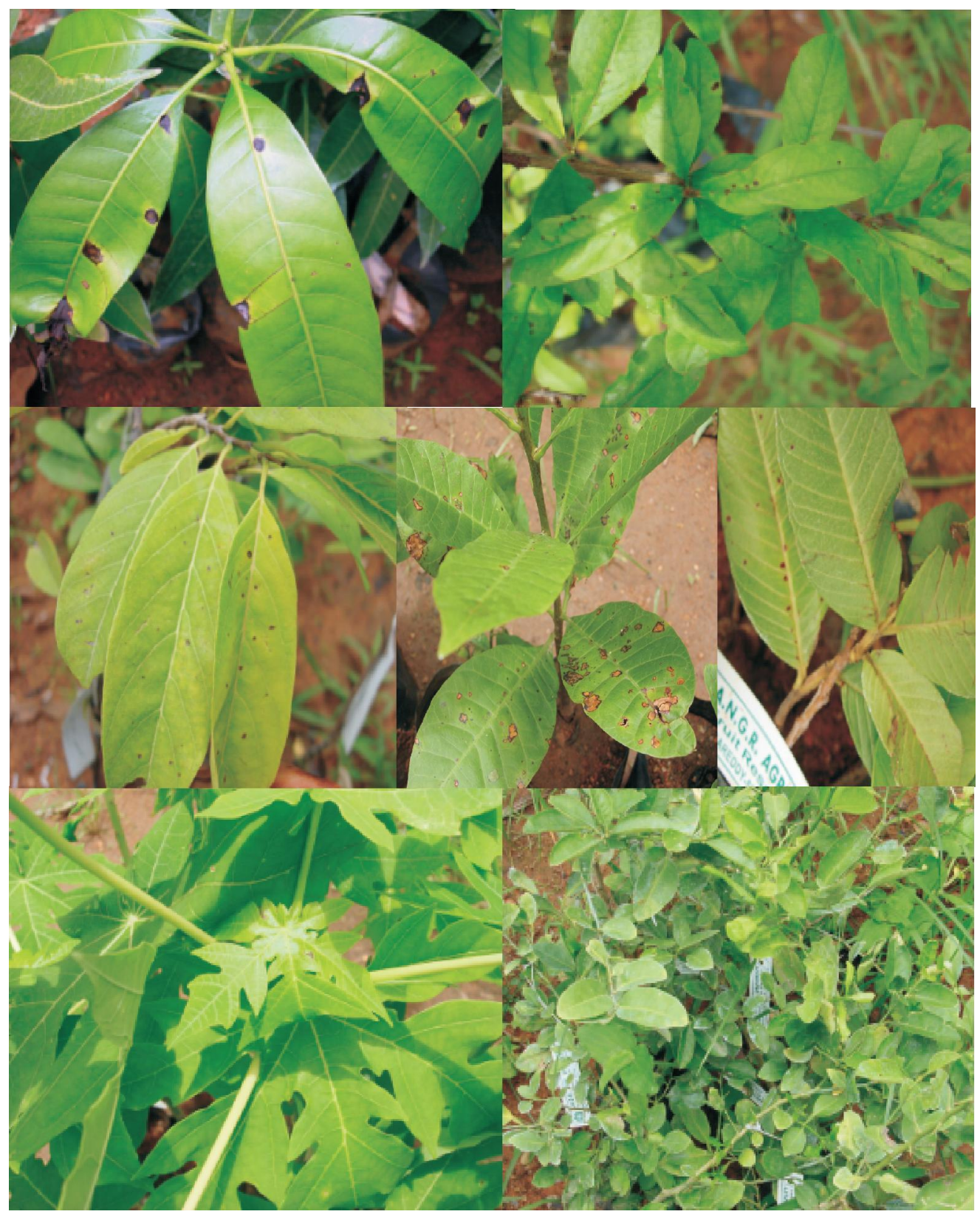

Plate 1. Pathogenicity of mango isolates of $C$. gloeosporioides on other fruit crops 

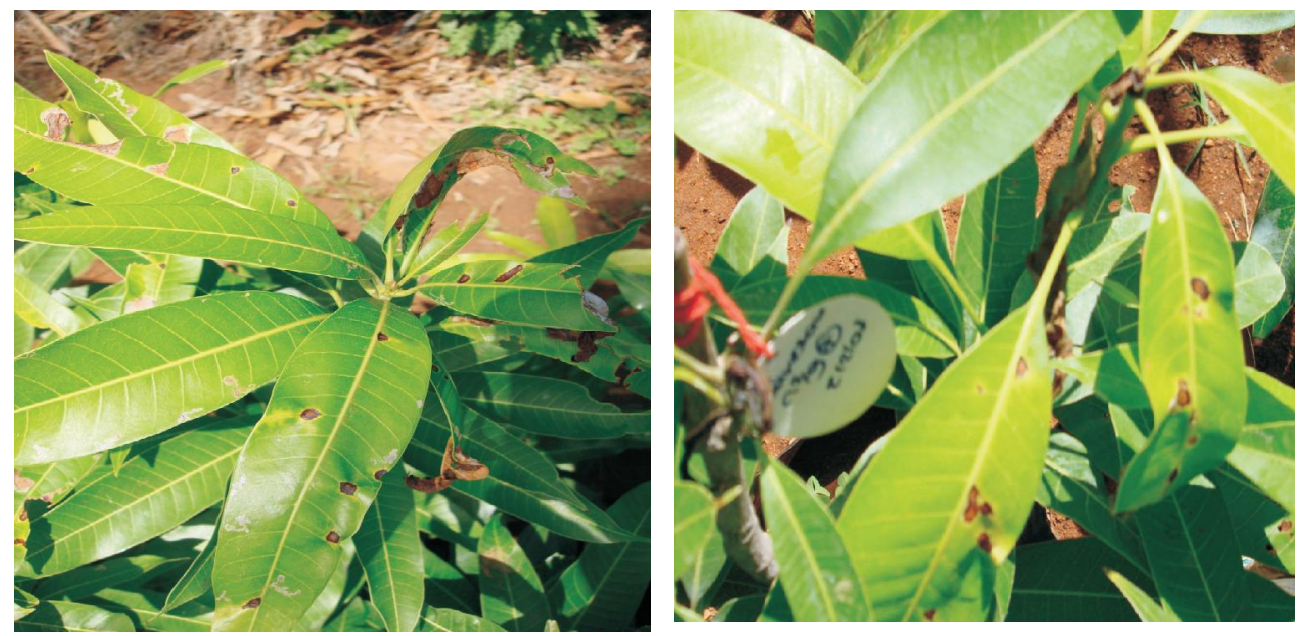

Plate 2. Symptoms developed by cashew and custard apple isolates of C. gloeosporioides on mango 